\title{
A New Method for Iron Loss Separation
}

Filomena B. R. Mendes ${ }^{1}$ (D), Fredy M. S. Suárez ${ }^{1}$ (D), Nelson J. Batistela ${ }^{2}$ (D) Jean V. Leite ${ }^{2}$ (D), Nelson Sadowski (D, João P. A. Bastos ${ }^{2}$ (1)

IUTFPR,DAELE,DAMAT,Pato Branco PR,85503-390,Brazil,,filomena@utfpr.edu.br,fredy@utfpr.edu.br,

${ }^{2}$ GRUCAD, EEL, UFSC, Florianópolis SC,PO.Box 476, 88040-970, Brazil, jhoe.batistela@ufsc.br, jean.vianei@ufsc.br,nelson.sadowski@ufsc.br,assumpcao.bastos@ufsc.br

\begin{abstract}
In this work we propose a new method to separate iron losses by removing low frequency tests and reducing the number of experiments. The article deals with methodologies that use numerical methods to find the mathematical model coefficients of magnetic loss separation in hysteresis loss $\left(W_{h}\right)$, eddy current loss $\left(W_{e d}\right)$ and excess loss $\left(W_{e x}\right)$. Three methodologies are presented and depend on experimental tests such as (i) varying magnetic induction $B_{m}$ and constant supply frequency $(f)$ of $50 \mathrm{~Hz}$, (ii) constant magnetic induction around $1 T$ and varying frequency. The first methodology is based on Newton's method to solve the numerical system generated with experimental data from two laboratory experiments. These data were reported in past references. Another two methodologies are based on genetic algorithms (GA). One of them depends on experimental data from both experiments and the another depends on experimental data only from experiment (i). Results indicate that genetic algorithms method presents excellent solutions in comparison with other ones. The GA method with two tests allows a better representation of the experimental behavior of the sample with maximum errors varying from $1.10 \%$ to $0.20 \%$. In GA method with one test, minimization varied from $6.924 \times 10^{-05}$ to $3.186 \times 10^{-05}$.
\end{abstract}

Index Terms — Genetic algorithms, iron losses, Newton's method.

\section{INTRODUCTION}

Electrical machines have ferromagnetic material core whose magnetic behavior has been investigated extensively [1]-[17]. Such studies model the magnetic behavior of the material, describe magnetic hysteresis phenomena and allow formulations for representing magnetic losses. Iron losses have been studied and there are steel test benches for electrical purposes operating with frequency variation, but do not allow ignoring dynamic losses. Iron losses are of key importance since they affect the design of electrical machines. In the last five years researches have been performed [1]-[3] in order to propose new iron losses models; they are compared with existing ones. In [1] the prediction of excess loss from three models were compared: two models on frequency domain and third one in time domain. The accuracy of the models was tested in sinusoidal and non-sinusoidal magnetic flux waveform. In [2] an iron loss model was developed considering the temperature influence on hysteresis and eddy current losses. The measured iron losses have shown that hysteresis and eddy current losses vary linearly with temperatures between 40 and $100{ }^{\circ} \mathrm{C}$. The advantage of this model is its utility on the analysis of electromagnetic and thermal coupling for predicting iron loss and 
temperature distribution on electrical machines. In [3], it is presented a procedure to determine losses on rotating magnetic fields in two and three dimensions based on classical methods of iron losses calculation.

This paper presents three methodologies of losses segregation that eliminate the hysteresis loss test at low frequency. Additionally, they do not require knowledge of the material's electrical conductivity to separate the different loss types. The first methodology, applying Newton's method, has been validated by using a reference strategy able to separate magnetic loss through three tests: total loss with variation of magnetic induction $\left(B_{m}\right)$ keeping a constant frequency (for example, $50 \mathrm{~Hz}$ ), hysteresis loss with variation of magnetic induction also keeping a constant frequency (for example, 1 $\mathrm{Hz}$ ) and total loss with variation of frequency, keeping a constant magnetic induction (for example, 1 T). The second methodology proposed in this paper applies the genetic algorithms (GA) method to separate magnetic loss using two tests. The third one here proposed applies a GA method to separate magnetic loss using only one test. For the validation of the methodologies, non-oriented sheet steel silicon tested in $25 \mathrm{~cm}$ Epstein frame is used. Comparing the results, it is observed that the first methodology outperforms the reference methodology. The second methodology presents a higher precision compared to the first one. There is a little difference between the second and the third methodologies.

\section{FIRST METHODOLOGY OF LOSS SEPARATION USING NEWTON'S METHOD: TWO TESTS}

Observing (1), silicon steel samples are inserted in the Epstein frame and submitted to the first test for determining the total loss constants, $k_{t}$ and $\alpha_{t}$. This test is performed by varying the magnetic induction $B_{m}$ and keeping the frequency value constant $\left(f_{t}=50 \mathrm{~Hz}\right)$. The total loss $W_{t}$, in $\mathrm{J} / \mathrm{kg}$, is measured for each value of magnetic induction $B_{m}$. The samples are submitted to the second test with frequency variation and keeping the induction constant $\left(B_{m f}=1 \mathrm{~T}\right)$ for selecting the loss separation. In this test, total loss $W_{t}$, in $\mathrm{J} / \mathrm{kg}$, is measured for each value of frequency $f_{\text {req }}$, in $\mathrm{Hz}$.

\section{A. Using data from first laboratory test}

Total loss is a function of magnetic induction and it is given by:

$$
W_{t}=k_{t} B_{m}^{\alpha_{t}}
$$

Let $n$ be the number of experimental points. For each experimental point $P_{i}\left(B_{m i}, W_{t i}\right)$, with $i=1, \ldots$, $n$, the logarithms $\ln \left(B_{m i}\right)$ and $\ln \left(W_{t i}\right)$ are calculated. These logarithms allow to calculate the total loss constants. To separate total loss in three components (hysteresis loss, eddy current loss and excess loss, respectively) the following equation is used:

$$
k_{t} B_{m}{ }^{\alpha}=k_{h} B_{m}^{\alpha}+k_{f} B_{m}^{2}+k_{e} B_{m}^{1.5}
$$

Since the total loss constants $\left(k_{t}, \alpha_{t}\right)$ have already been determined, four constants remain to be determined: $k_{h}, \alpha, k_{f}$ and $k_{e}$. To do so, the following system of non-linear equations using Newton's method is solved: 


$$
\vec{F}=\left[\begin{array}{l}
k_{h} 0.4^{\alpha}+k_{f} 0.4^{2}+k_{e} 0.4^{1.5}-k_{t} 0.4^{\alpha_{t}} \\
k_{h} 0.73^{\alpha}+k_{f} 0.73^{2}+k_{e} 0.73^{1.5}-k_{t} 0.73^{\alpha_{t}} \\
k_{h} 1.067^{\alpha}+k_{f} 1.067^{2}+k_{e} 1.067^{1.5}-k_{t} 1.067^{\alpha_{t}} \\
k_{h} 1.4^{\alpha}+k_{f} 1.4^{2}+k_{e} 1.4^{1.5}-k_{t} 1.4^{\alpha_{t}}
\end{array}\right]=\left[\begin{array}{l}
f_{1} \\
f_{2} \\
f_{3} \\
f_{4}
\end{array}\right]
$$

Let $\vec{x}_{k}=\left[\mathrm{k}_{h k}, \alpha_{k}, \mathrm{k}_{f k}, \mathrm{k}_{e k}\right]$. In this method there are stopping criteria to accept a given point $\vec{x}_{k}=\left[\mathrm{k}_{h k}, \alpha_{k}, \mathrm{k}_{f k}, \mathrm{k}_{e k}\right]$ as the better approximation of the exact solution $\vec{x}^{*}$ and to detect divergence. Since $\vec{F}\left(\vec{x}^{*}\right)=\overrightarrow{0}$, a stopping criterion is necessary to verify if all the components of $\vec{F}\left(\vec{x}_{k}\right)$ have a module of small dimension. To detect divergence and interrupt calculation, test with a maximum number of iterations is used.

\section{B. Using data from second laboratory test}

The system in (3) presents several solutions. Nevertheless, there is only one physically real solution that satisfies the model in (2). The strategy, here described, allows finding the physical real solution by selecting the loss separation that matches the curve of experimental points obtained by varying frequency test with a constant magnetic induction $\left(B_{m f}=1 \mathrm{~T}\right)$. Let $n_{f}$ be the number of experimental points. For an experimental point $P_{i}\left(f_{\text {req }(i)}, W_{t f(i)}\right)$ with $i=1, \ldots, n_{f}$, the following is calculated:

$$
\begin{gathered}
W_{t}(i)=k_{h}\left(B_{m f}\right)^{\alpha}+\frac{f_{r e q}(i)}{f_{t}} k_{f}\left(B_{m f}\right)^{2}+\sqrt{\frac{f_{r e q}(i)}{f_{t}}} k_{e}\left(B_{m f}\right)^{1.5} \\
\operatorname{erro}(i)=a b s\left(\left(W_{t f}(i)-W_{t}(i)\right) / W_{t f}(i)\right)
\end{gathered}
$$

Upon calculating several solutions of the system (3), the solution that presents lowest error given by (5) is selected.

\section{SECOND LOSS SEPARATION METHODOLOGY USING GA: TWO TESTS}

\section{A. Using data from first laboratory test}

Total loss constants $k_{t}$ and $\alpha_{t}$ are calculated in a similar way as presented in II-A.

\section{B. Using data from second laboratory test}

GA method is used for calculating the four constants of magnetic losses $\left(k_{h}, \alpha, k_{f}, k_{e}\right)$ which minimize the sum of the relative error between the calculated total loss $W_{t}$ and experimental total loss $W_{t f}$. Equation (6) is the objective function to be minimized.

$$
g(\vec{x})=g_{1}(\vec{x})+\cdots+g_{n_{f}}(\vec{x})=\sum_{i=1}^{n_{f}}\left|\frac{W_{t f}(i)-W_{t}(i)}{W_{t f}(i)}\right|
$$

subject to: $0.001 \leq k_{h} \leq 0.1 ; 1 \leq \alpha \leq 2 ; 0.0004 \leq k_{f} \leq 0.01 ; 0.0001 \leq k_{e} \leq 0.01$ in which $n_{f}$ is the number of points from loss test with frequency variation keeping the magnetic induction constant at $1 \mathrm{~T}$. The calculated total loss $W_{t}$ is given by (4). Positive nonzero real number is the criterion to choose the range of the coefficients $k_{h}, \alpha, k_{f}$ and $k_{e}$.

In GA methods, each calculation step is called generation. First generation is built randomly, its Brazilian Microwave and Optoelectronics Society-SBMO received 18 Jan 2021; for review 18 Jan 2021; accepted 3 May 2021 
population is evaluated, and each chromosome receives a fitness score that reflects the solution quality represented by the chromosome. Fittest chromosomes are selected and modified through crossover and mutation operators producing children that make up the next generation. The process repeats until a satisfactory solution is found. Found constant losses are inserted in (4) to compare the calculated total losses with experimental total losses $W_{t f}$ obtained from the frequency variation test at constant $B_{m f}=1 \mathrm{~T}$.

\section{THIRD LOSS SEPARATION METHODOLOGY USING GA: SINGLE TEST}

\section{A. Using data from first laboratory test}

Total loss constants $k_{t}$ and $\alpha_{t}$ are calculated in a similar way as presented at section II-A.

GA method is used for calculating the four magnetic losses constants $\left(k_{h}, \alpha, k_{f}, k_{e}\right)$ that minimize the infinity norm of $\vec{F}$ given by (3). The equation (7) below is minimized.

$$
g(\vec{x})=\|\vec{F}\|_{\infty}=\max \left|f_{m}\right|, 1 \leq m \leq 4
$$

subject to: $0.001 \leq k_{h} \leq 0.1 ; 1 \leq \alpha \leq 2 ; 0.0004 \leq k_{f} \leq 0.01 ; 0.0001 \leq k_{e} \leq 0.01$.

Infinity norm of $\vec{F}$ is the component of maximum absolute value. Minimization of $\vec{F}$ infinity norm is appropriated because $\vec{x}^{*}$ is an exact solution of system (3) and therefore $\vec{F}\left(\vec{x}^{*}\right)=\overrightarrow{0}$. If the maximum absolute value of $\vec{F}(\vec{x})$ component is minimized, the approximated solution of system (3) is reached. In other words, to know if a given vector is near the null vector, verifying its maximum absolute value component is sufficient.

Steps presented in III-B are also followed to minimize (7). The principal distinction observed between the method presented in III and the current one is the objective function. Observe that (7) does not require experimental data from the second test. Consequently, this method requires experimental data only from the performed test varying the magnetic induction and keeping constant the frequency $\left(f_{t}=50 \mathrm{~Hz}\right)$.

\section{REFERENCE METHODOLOGY FOR LOSS SEPARATION: THREE TESTS}

\section{A. Using data from first laboratory test}

In the reference strategy for loss separation, hysteresis loss is obtained in a relatively low frequency, for example $1 \mathrm{~Hz}$, when dynamic losses (Eddy current loss and excess loss) can be disregarded. From Steinmetz model the hysteresis loss is given: $W_{h}=k_{h} B_{m}{ }^{\alpha}$.

Hysteresis loss constants $k_{h}$ and $\alpha$ are obtained in a similar way as presented in the section II-A for determining total loss constants.

\section{B. Using data from second laboratory test}

The total loss is obtained from the material test in a relatively high frequency $(50 \mathrm{~Hz})$, where dynamic losses can be easily detected. The total loss evolution can be represented by (2). The procedure to obtain total loss constants $k_{t}$ and $\alpha_{t}$ is similar to the procedure presented in II-A. 


\section{Using data from third laboratory test}

Knowing the constants $k_{t}, \alpha_{t}, k_{h}$ and $\alpha,(8)$ is obtained from (2).

$$
k_{e}=\left(k_{t} B_{m}{ }^{\alpha_{t}}-k_{h} B_{m}{ }^{\alpha}\right) / B_{m}{ }^{1.5}-k_{f} B_{m}^{0.5}
$$

In (8), it is still necessary to find the value of two constants $k_{e}$ and $k_{f}$. Then, (8) is written as an equation given by: $k_{e}=a_{f e}+b_{f e} k_{f}$. When the graph of this line is drawn, it is noted that the line cuts the vertical (variable $k_{e}$ axis) and horizontal axis (variable $k_{f}$ axis) at a certain point. For determining the constants $k_{e}$ and $k_{f}$, the intersection points between line and axes must be excluded and the remaining pairs $\left(k_{e}, k_{f}\right)$ placed only in first quadrant must be found. From the line it is possible to extract a segment that contains all the physical possible pairs $\left(k_{e}, k_{f}\right)$. Nevertheless, to choose one single ordered pair corresponding to the tested material, it is necessary to lift experimental total loss curve (varying frequency $f_{\text {req }}$ ) as well as to calculate total loss by (4) with the pair. Therefore, an ordered pair $\left(k_{f}, k_{e}\right)$ that minimizes the error between these curves (experimental total loss and calculated total loss) is selected.

\section{RESULTS}

In order to acquire experimental data, a workbench developed for the characterization of magnetic materials and losses measurements have been implemented. This workbench communicates with a microcomputer where the material characterization programs run with Labview (National Instruments software). An Epstein's frame using 28-cm-long, 3-cm-wide iron sheets is part of the workbench. This frame has 700 turns at the primary $\left(N_{p}\right)$ and in the same number at the secondary $\left(N_{s}\right)$, with a magnetic mean path of $0.94 \mathrm{~m}$. The primary winding has a $0.691 \Omega$ electrical resistance.

Labview is installed in a computer connected to a multiple channel oscilloscope. The voltages and currents at primary and secondary windings are measured simultaneously with this oscilloscope and peripheric devices. The magnetic quantities are obtained from the electrical ones. The magnetic losses (power) are obtained by electrical signals digital processing. At the end of the appendix, the photography of the workbench used to acquire the experimental data is shown.

The eddy current as well as the stray losses can be obtained at different frequencies for different magnetic flux density levels. The hysteresis losses are obtained for different magnetic flux density levels at low frequency, called quasi-static tests (usually under $5 \mathrm{~Hz}$ ), when the dynamic losses can be neglected.

More details about the workbench and experimental procedures can be obtained in [16], [17].

For the purpose of separating total magnetic loss $\left(W_{\text {total }}\right)$ in: hysteresis loss $\left(W_{h}\right)$, Eddy current loss $\left(W_{e d}\right)$ and excess loss $\left(W_{e x}\right)$, the three methodologies presented were applied to four cases. In Fig. 1-13 and Tables I-II the results can be observed: losses constants $\left(k_{t}, \alpha_{t}, k_{h}, \alpha, k_{f}, k_{e}\right)$, value of maximum error and a comparison among the methodologies.

For the first case, using the reference strategy, the results presented in Fig. 1.a and Table I were obtained. It can be observed that, up to $1.2 \mathrm{~T}$, there is a good agreement between the model and 
measured points. In Fig. 1.b the calculated loss presents an acceptable agreement with the measured curve, with the maximum error of $6.50 \%$.

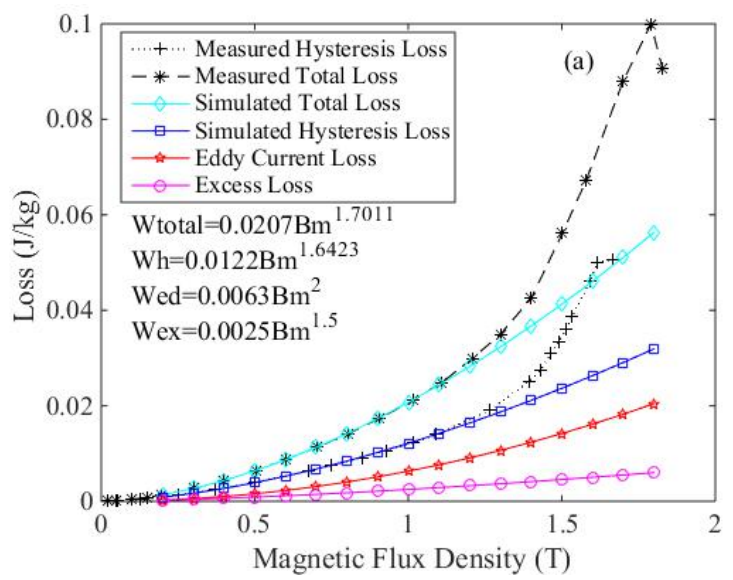

(a)

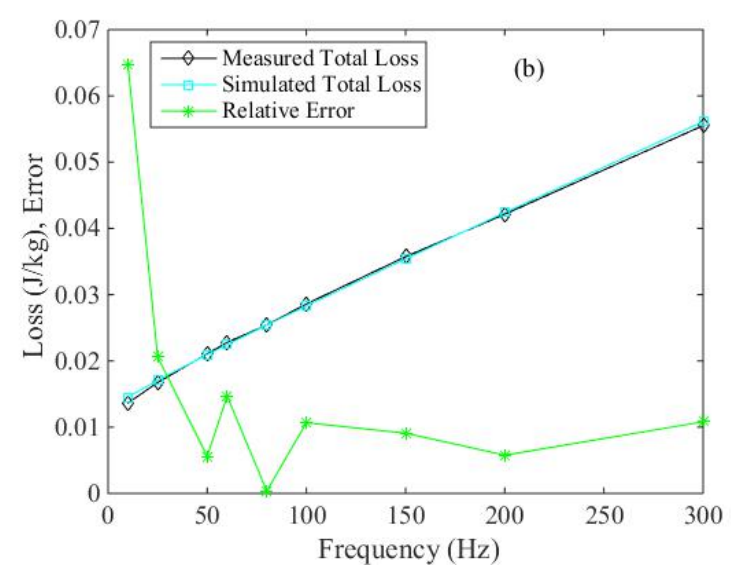

(b)

Fig. 1. First case. Reference strategy: (a) loss separation, (b) relative error.

TABLE I. COMPARISON AMONG METHODOLOGIES

\begin{tabular}{cccccccc}
\hline \multirow{2}{*}{ Case } & \multicolumn{2}{c}{$\begin{array}{c}\text { Reference: } \\
\text { 3 tests }\end{array}$} & \multicolumn{2}{c}{$\begin{array}{c}\text { GA: } \\
\text { 2 tests }\end{array}$} & \multicolumn{2}{c}{$\begin{array}{c}\text { Newton: } \\
\text { 2 tests }\end{array}$} & $\begin{array}{c}\text { GA: } \\
\text { 1 test }\end{array}$ \\
\cline { 2 - 8 } & Agree & Error & Agree & Error & Agree & Error & Agree \\
\hline $1^{\circ}$ & $1.2 \mathrm{~T}$ & $6.50 \%$ & $1.3 \mathrm{~T}$ & $1.10 \%$ & $1.2 \mathrm{~T}$ & $5.20 \%$ & $1.3 \mathrm{~T}$ \\
$2^{\circ}$ & - & - & $1.3 \mathrm{~T}$ & $1.00 \%$ & $1.3 \mathrm{~T}$ & $10.00 \%$ & $1.3 \mathrm{~T}$ \\
$3^{\circ}$ & - & - & $1.3 \mathrm{~T}$ & $0.23 \%$ & $1.3 \mathrm{~T}$ & $7.80 \%$ & $1.3 \mathrm{~T}$ \\
$4^{\circ}$ & - & - & $1.3 \mathrm{~T}$ & $0.20 \%$ & $1.3 \mathrm{~T}$ & $5.40 \%$ & $1.3 \mathrm{~T}$ \\
\hline
\end{tabular}

Figure 3 presents the results with the application of the first methodology (Newton) for the first case. It is observed that it reached a set of parameters that represents the losses curves even with better result when compared with the obtained using the reference strategy, shown in Fig. 1.

In Fig. 6.b it can be noticed that for Newton's method the maximum error is 0.10 and for GA method, Fig. 5.b, the maximum error is 0.010 . Observing Newton's method together with GA method, which uses data from two tests, the following difference is established: in all analyzed and presented cases of Table I, the GA method allows a better representation of the experimental behavior of the sample.

For Fig. 4, 7, 10 and 13 the objective function values are respectively: $3.186 \times 10^{-05}, 6.924 \times 10^{-05}$, $4.478 \times 10^{-05}$ and $5.066 \times 10^{-05}$.

In the first case the samples were inserted in Epstein frame with all sheets cut in longitudinal direction. The second case is related to the material E230-C0 of thickness $479.29 \mu \mathrm{m}$. The third case deals with material CPGXH-4 of thickness $492 \mu \mathrm{m}$ with half of sheets stamped on the direction of lamination and remaining sheets stamped on the transverse direction. And the fourth case the material BGJPX83-F with a thickness of $520 \mu \mathrm{m}$ is used. There is also a single sheet tester but it was not used in this paper.

The calculated total loss represents total loss curve measured up to $1.3 \mathrm{~T}$. Depending on the 
material, it is known that $k_{h} B_{m}{ }^{\alpha}$ may not represent the losses evolution for the entire magnetic induction range until saturation. After saturation, hysteresis loss do not keep increasing as it is calculated by $k_{h} B_{m}{ }^{\alpha}$. For the first case, the advantage of GA method is to represent total loss curve measured up to $1.3 \mathrm{~T}$ while other methods represent only up to $1.2 \mathrm{~T}$. This occurs because the methods calculate coefficients $k_{h}, \alpha, k_{f}$ and $k_{e}$ by different procedures: in Newton's method the system (3) is solved, in GA method (6) or (7) is minimized and in the reference strategy (8) is used.
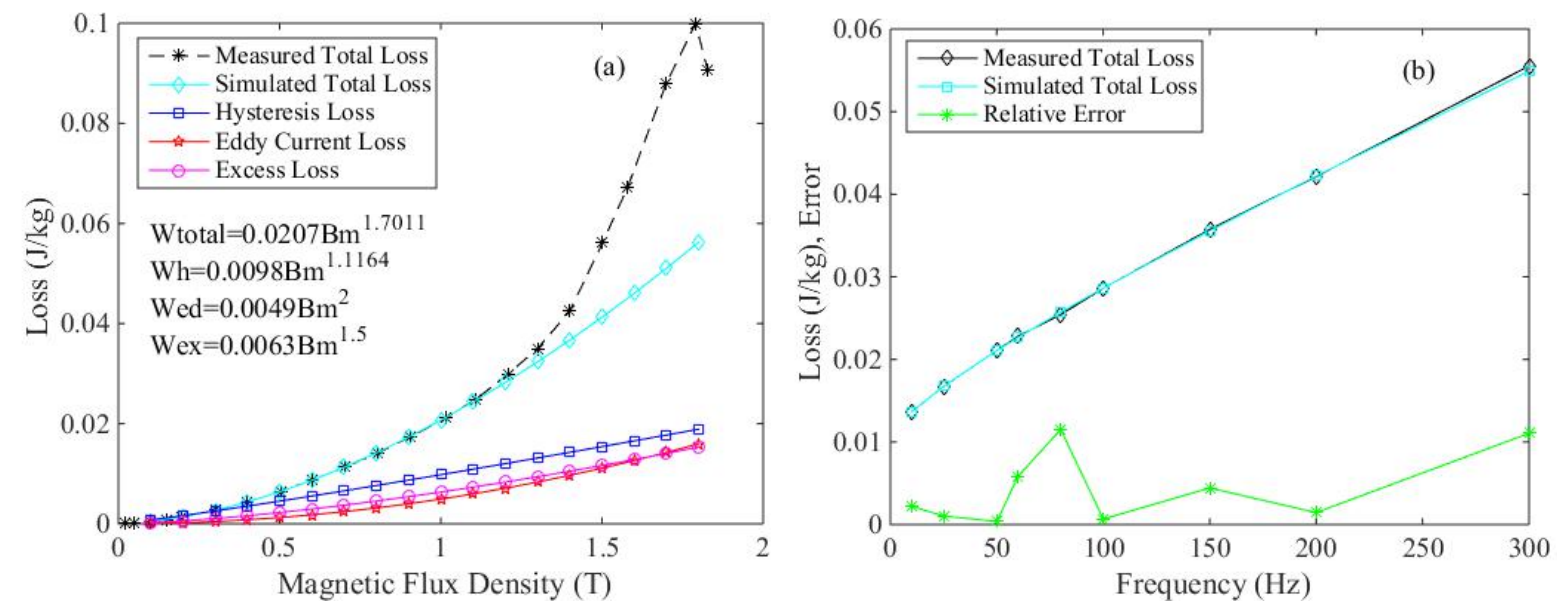

Fig. 2. First case. GA. Two tests: (a) loss separation, (b) relative error.
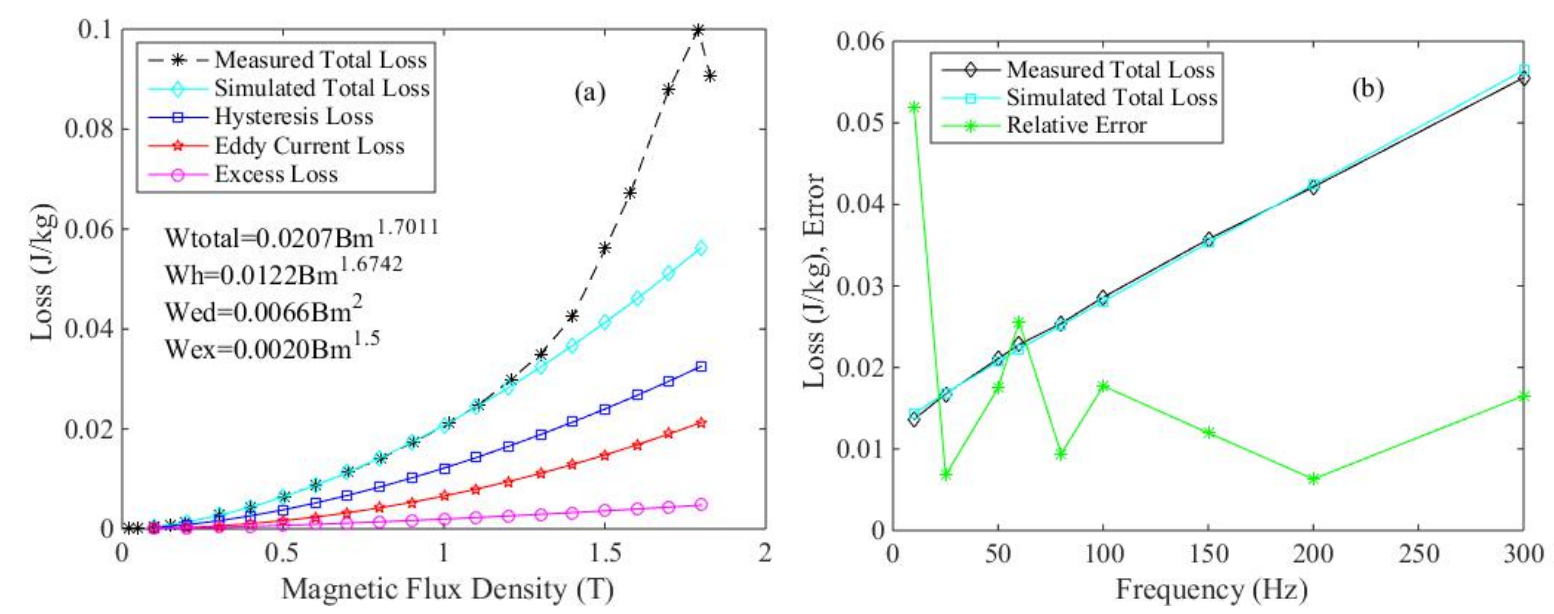

Fig. 3. First case. Newton's method: (a) loss separation, (b) relative error.

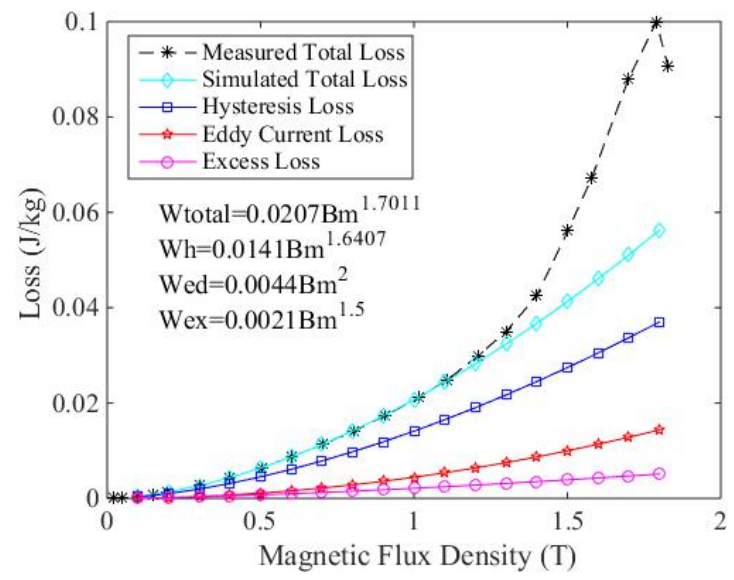

Fig. 4. First case. GA. One test: loss separation. 

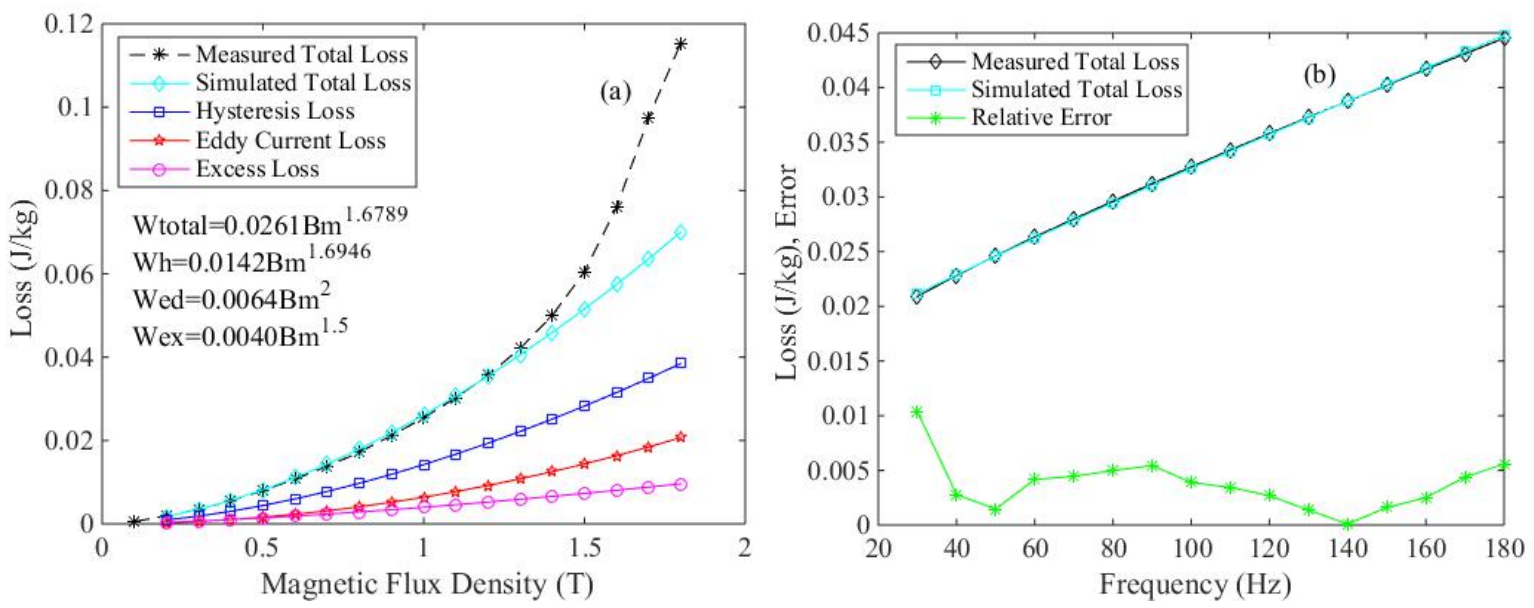

Fig. 5. Second case. GA. Two tests: (a) loss separation, (b) relative error.
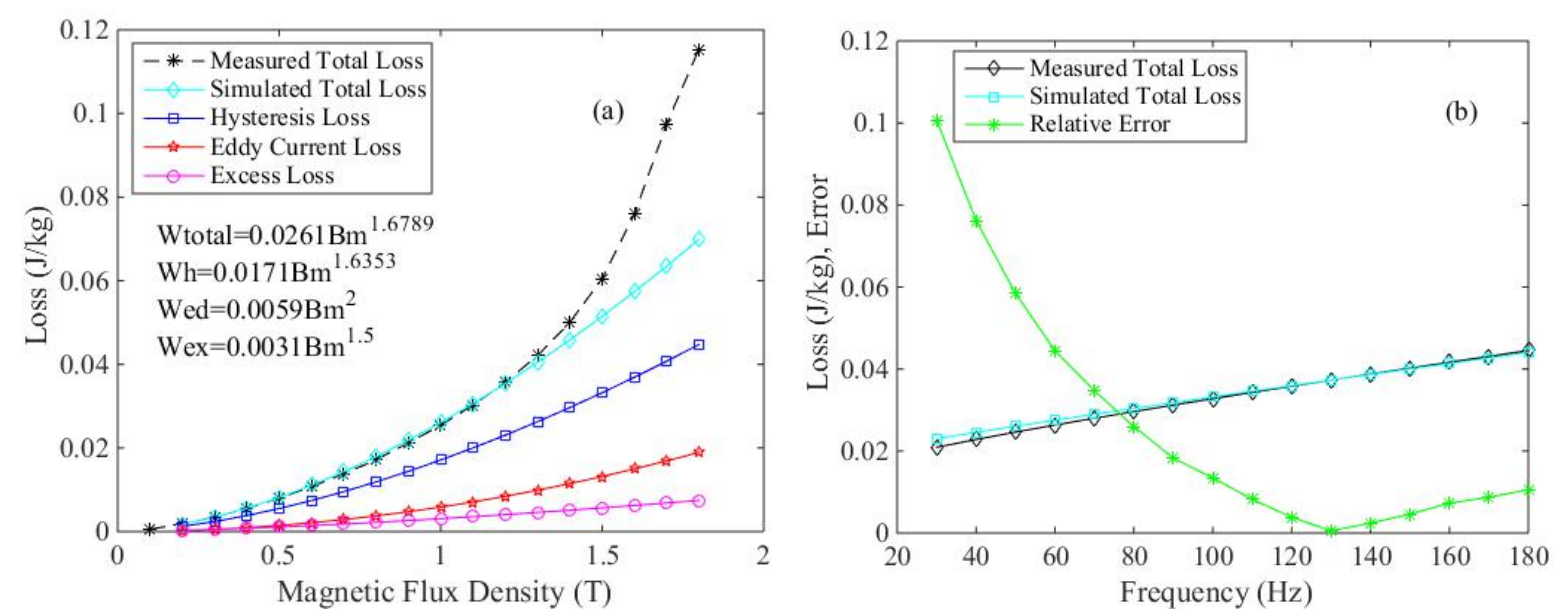

Fig. 6. Second case. Newton's method: (a) loss separation, (b) relative error.

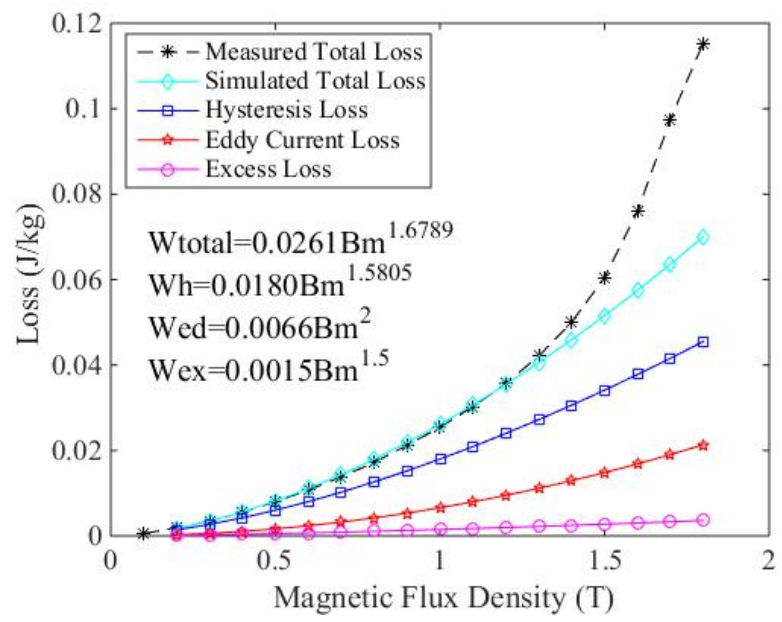

Fig. 7. Second case. GA. One test: loss separation. 
Journal of Microwaves, Optoelectronics and Electromagnetic Applications, Vol. 20, No. 4, December 2021
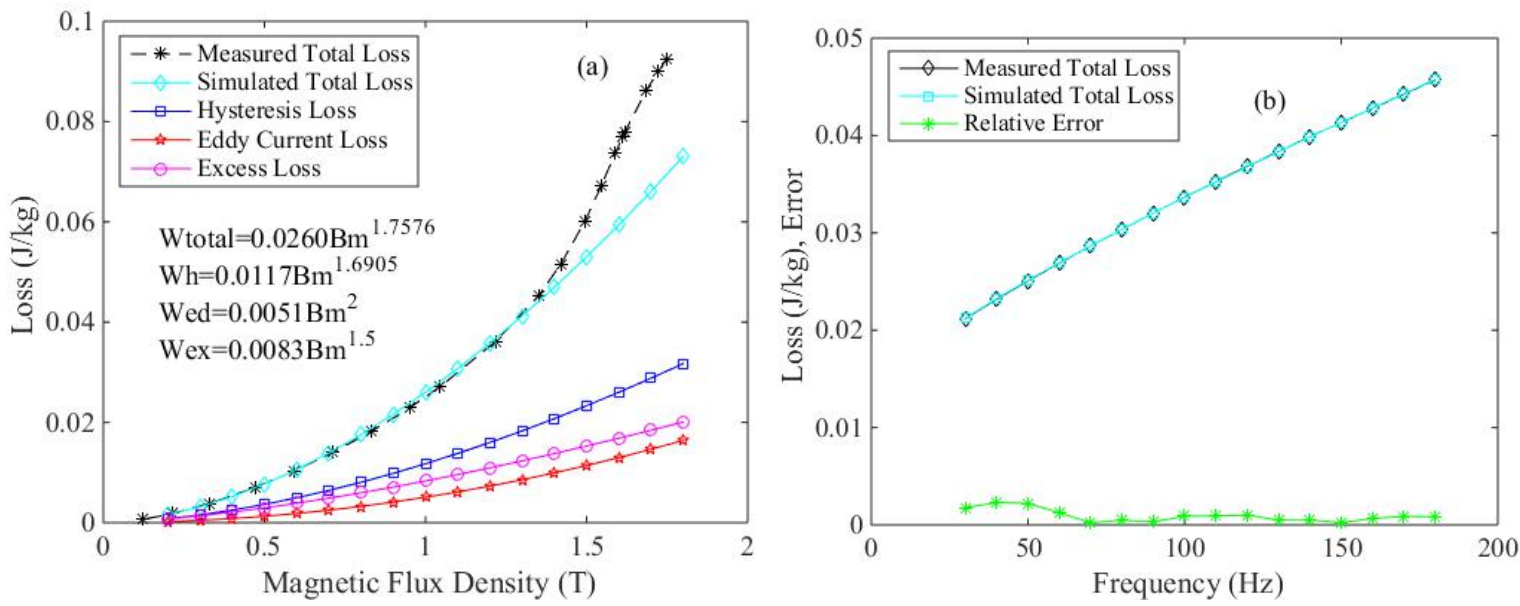

Fig. 8. Third case. GA. Two tests: (a) loss separation, (b) relative error.
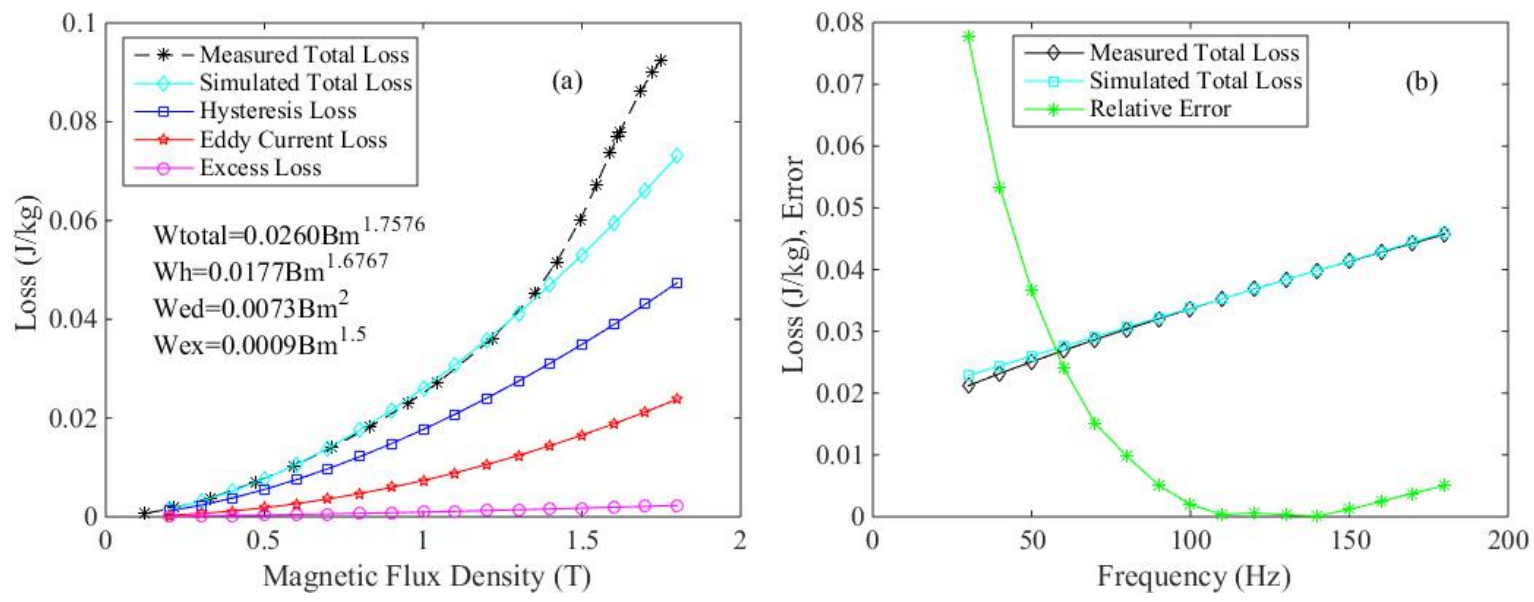

Fig. 9. Third case. Newton's method: (a) loss separation, (b) relative error.

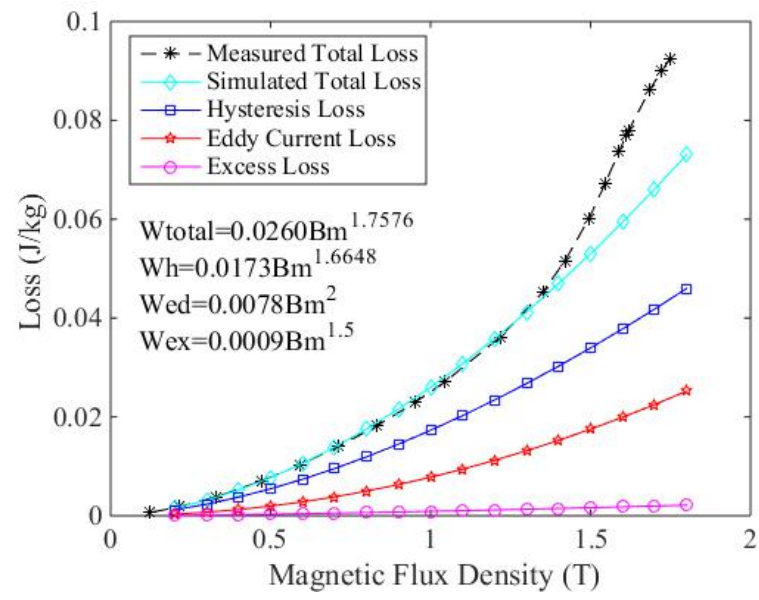

Fig. 10. Third case. GA. One test: loss separation. 

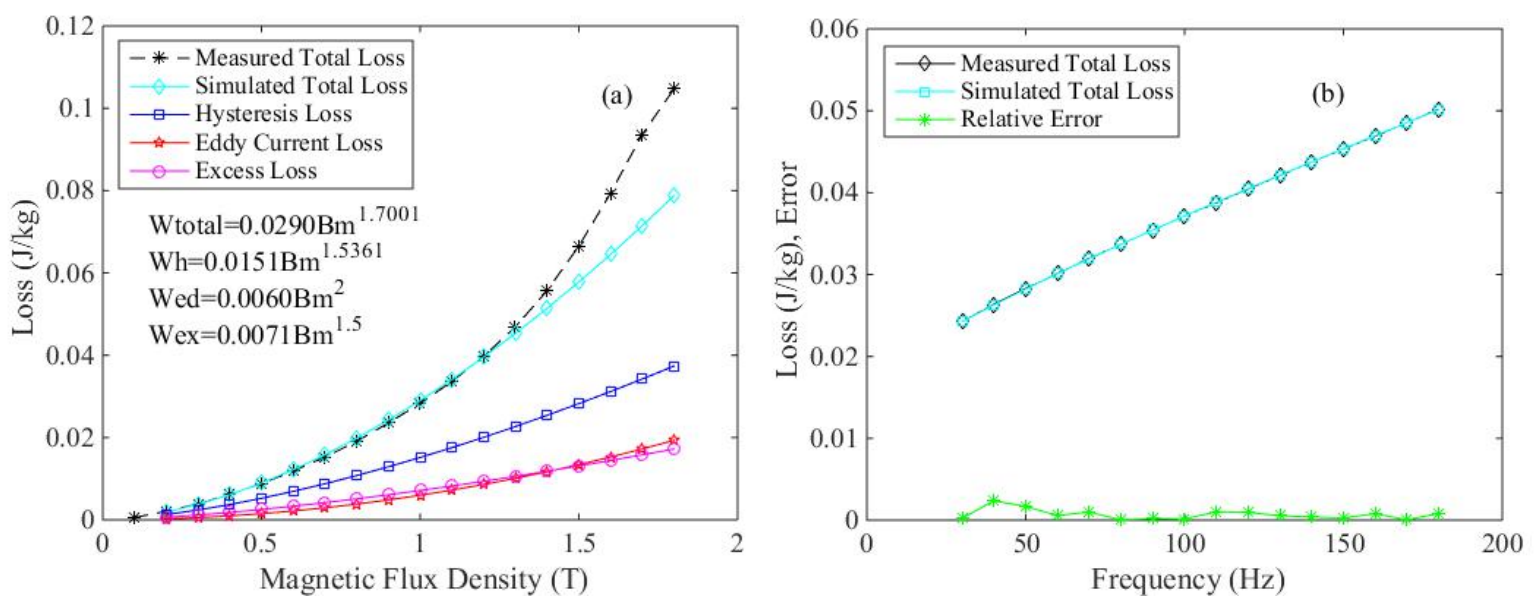

Fig. 11. Fourth case. GA. Two tests: (a) loss separation, (b) relative error.
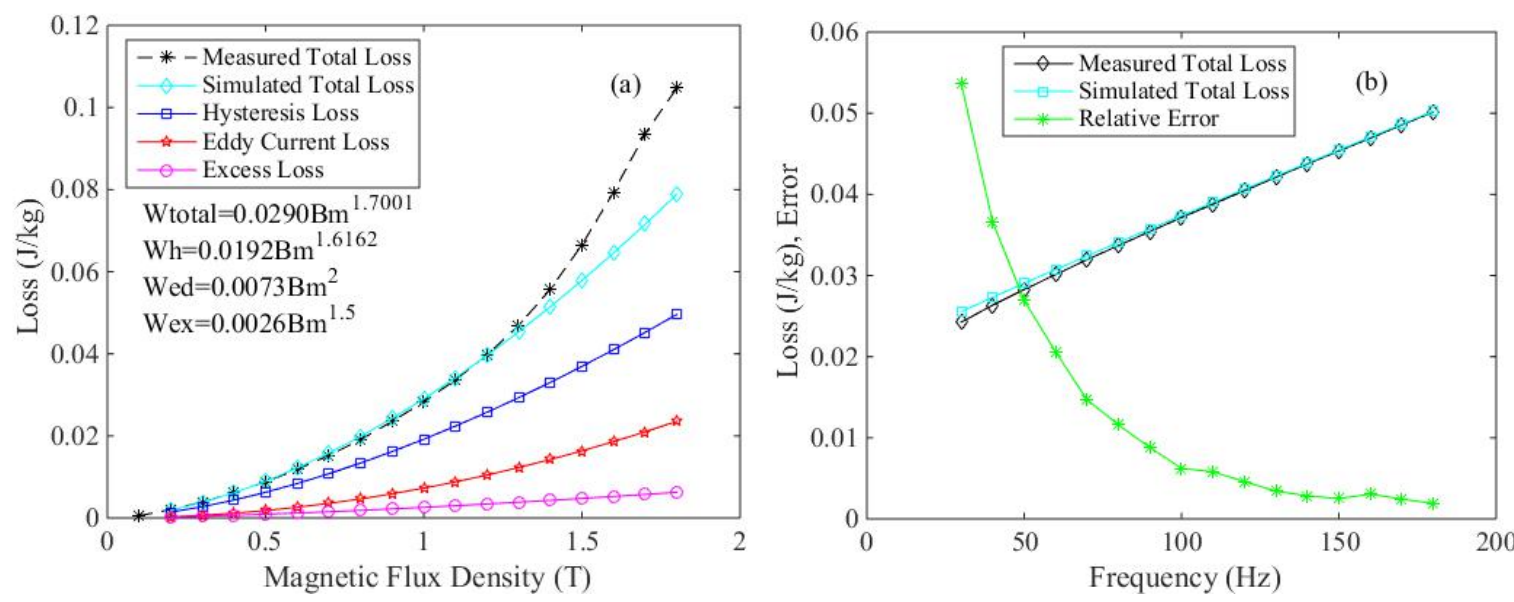

Fig. 12. Fourth case. Newton's method: (a) loss separation, (b) relative error.

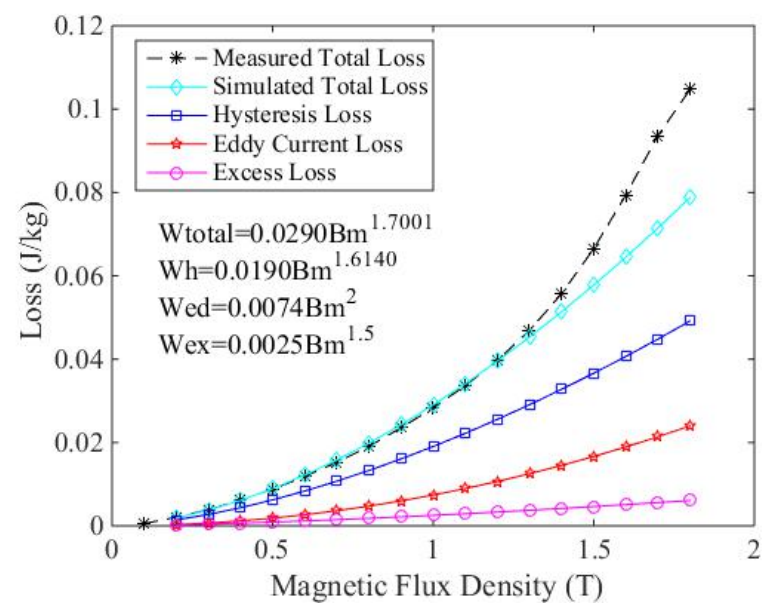

Fig. 13. Fourth case. GA. One test: loss separation.

In Figs. 8 and 11 it can be observed that the relative error is almost zero. Consequently, the constant losses obtained by GA method can be considered the more accurate values. The GA method using data from two laboratory tests is compared to the GA method with one laboratory test. The differences are presented in Table II. The largest difference is 0.52 in loss hysteresis exponent of the first case. As the largest difference is smaller than the unit and this happened with samples of four different 
materials, one can conclude that it is permissible to separate magnetic losses using a single test at 50 $\mathrm{Hz}$ (varying magnetic induction and keeping the frequency constant). To need only one test reduces costs and time during obtaining parameters process.

TABLE II. COMPARISON OF LOSSES CONSTANTS

\begin{tabular}{|c|c|c|c|c|c|}
\hline & & \multicolumn{2}{|c|}{ Genetic Algorithms } & \multirow{2}{*}{ Difference } & \\
\hline & & Two Electrical Testing & One Electrical Testing & & \\
\hline \multirow{4}{*}{ 1st case } & $k_{h}$ & 0.0098 & 0.0141 & -0.0043 & Increase \\
\hline & $\alpha$ & 1.1164 & 1.6407 & -0.5243 & Increase \\
\hline & $k_{f}$ & 0.0049 & 0.0044 & 0.0005 & Decrease \\
\hline & $k_{e}$ & 0.0063 & 0.0021 & 0.0042 & Decrease \\
\hline \multirow{4}{*}{ 2nd case } & $k_{h}$ & 0.0142 & 0.018 & -0.0038 & Increase \\
\hline & $\alpha$ & 1.6946 & 1.5805 & 0.1141 & Decrease \\
\hline & $k_{f}$ & 0.0064 & 0.0066 & -0.0002 & Increase \\
\hline & $k_{e}$ & 0.004 & 0.0015 & 0.0025 & Decrease \\
\hline \multirow{4}{*}{ 3rd case } & $k_{h}$ & 0.0117 & 0.0173 & -0.0056 & Increase \\
\hline & $\alpha$ & 1.6905 & 1.6648 & 0.0257 & Decrease \\
\hline & $k_{f}$ & 0.0051 & 0.0078 & -0.0027 & Increase \\
\hline & $k_{e}$ & 0.0083 & 0.0009 & 0.0074 & Decrease \\
\hline \multirow{4}{*}{ 4th case } & $k_{h}$ & 0.0151 & 0.019 & -0.0039 & Increase \\
\hline & $\alpha$ & 1.5361 & 1.614 & -0.0779 & Increase \\
\hline & $k_{f}$ & 0.006 & 0.0074 & -0.0014 & Increase \\
\hline & $k_{e}$ & 0.0071 & 0.0025 & 0.0046 & Decrease \\
\hline
\end{tabular}

\section{CONCLUSION}

In this paper three methodologies were presented to predict iron losses and separate them into three components and eliminating the low frequency test. The precision obtained in the prediction of total loss experimental curves as function of frequency is excellent and consequently increases the reliability of the obtained losses constants. Separating magnetic losses without the need of low frequency test data $(1 \mathrm{~Hz})$ is a relevant advance in the area of magnetic material modeling. The main contributions of this paper are: the use of GA for the optimization of the estimated losses coefficients and the reduction of tests by the use of the infinity norm optimization. This paper has shown that GA is an effective tool to estimate the losses coefficients of iron. The paper describes a new approach for determining the iron loss through Epstein frame. Three methodologies were compared to evaluate the parameters representing the total amount of losses considering three different parcels, like hysteresis, eddy current losses, and excess losses. The authors believe that this paper significantly contributes with an important activity of electrical machines manufacturers which is the identification of different kind of iron losses, even more when nowadays many of them are electronically driven and submitted to harmonics.

\section{APPENDIX}

In Fig. 14 the main steps of a numerical procedure to calculate the total loss constants can be observed. It is necessary to linearize the total loss curve $W_{t}$ as a function of the induction $B_{m t}$.

In Fig. 15 the main steps of a numerical procedure to calculate loss constants $k_{h}, \alpha, k_{f}$ and $k_{e}$ using Newton's method is presented. To determine these values the system of nonlinear equations $F$ is solved by using four values of magnetic induction: $0.4,0.73,1.067$ and $1.4 \mathrm{~T}$. 
In Fig. 16 the main steps of a numerical procedure to calculate loss constants $\left(k_{h}, \alpha, k_{f}, k_{e}\right)$ that minimize the sum of the relative error between the calculated total loss $W_{t}$ and experimental total loss $W_{t f}$ are described. GA method and two laboratory tests are used.

In Fig. 17 the main steps of a numerical procedure to calculate loss constants $\left(k_{h}, \alpha, k_{f}, k_{e}\right)$ using GA method and a single laboratory test can be observed.

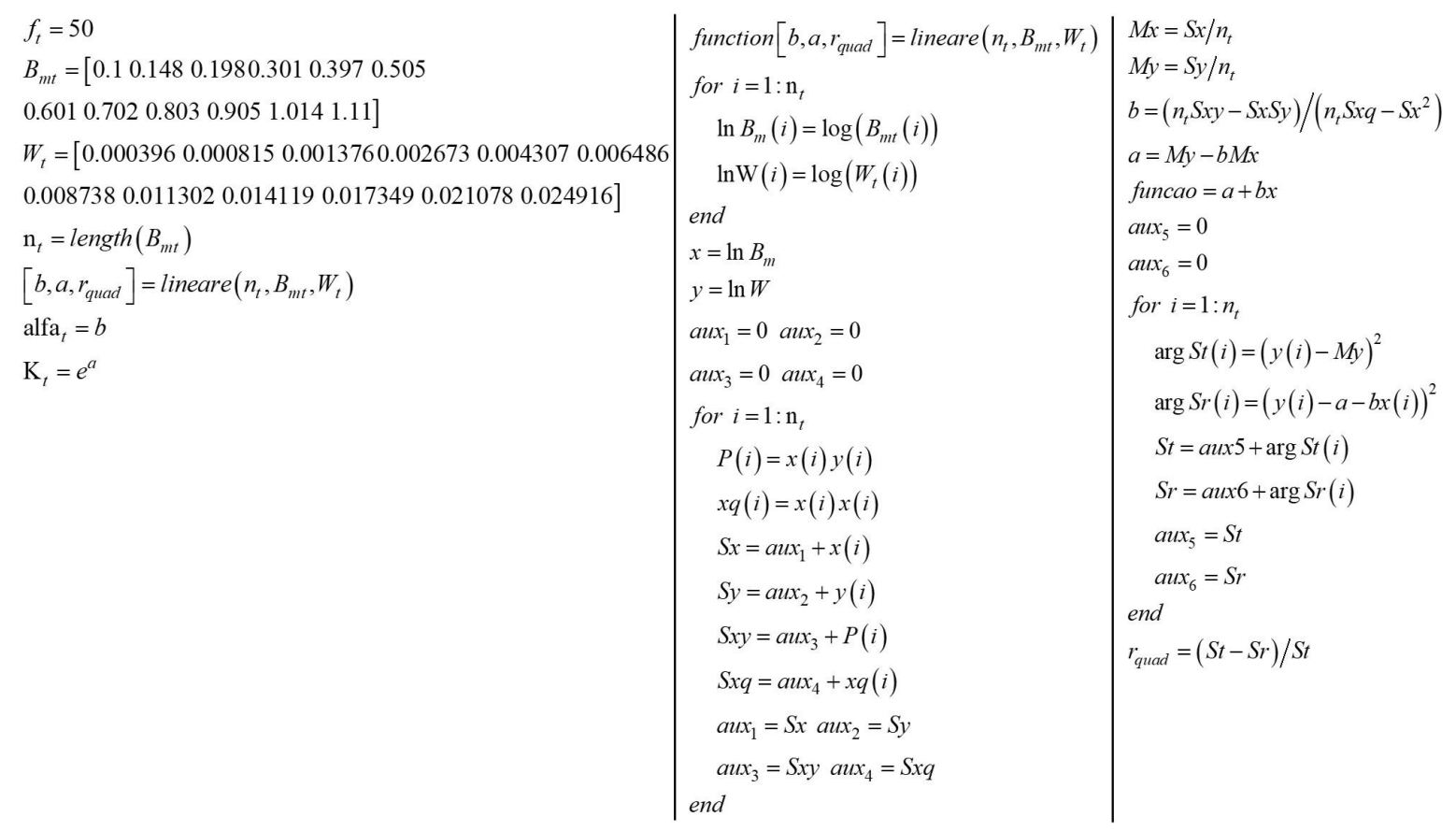

Fig. 14. Procedure for obtaining total loss constants.
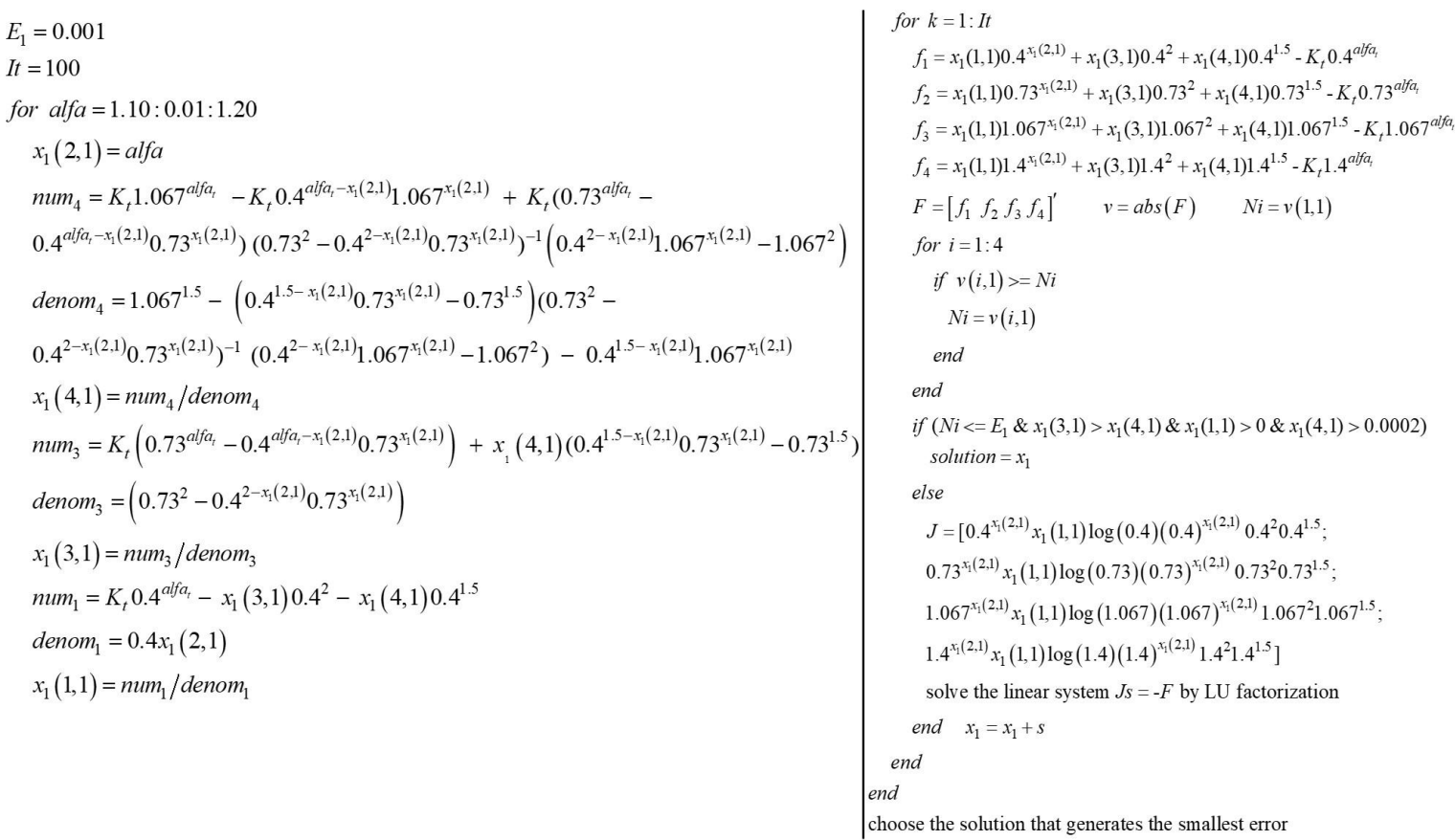

Fig. 15. Procedure of Newton's method. 
Journal of Microwaves, Optoelectronics and Electromagnetic Applications, Vol. 20, No. 4, December 2021 DOI: http://dx.doi.org/10.1590/2179-10742021v20i4254770

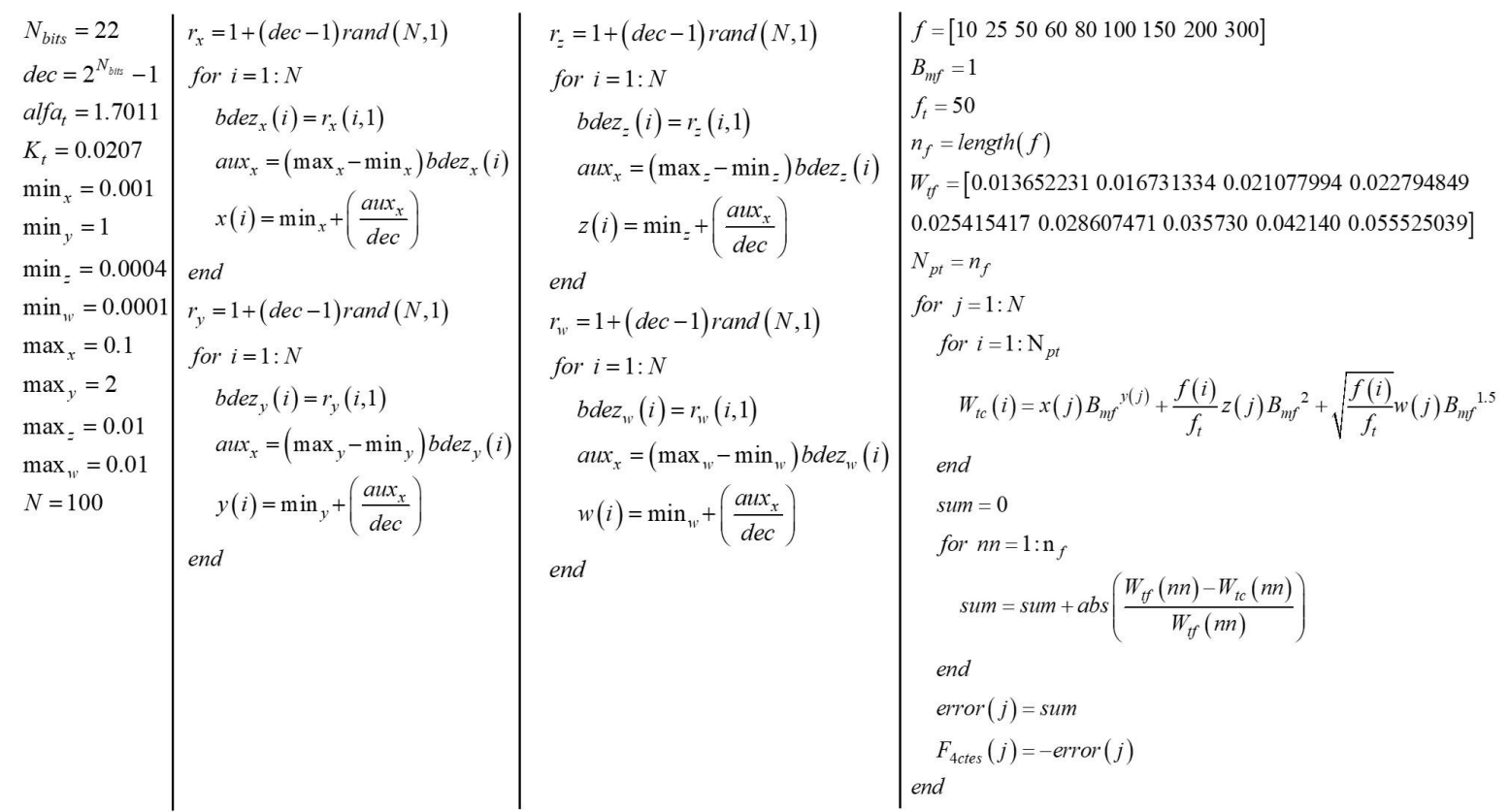

Fig. 16. Procedure of GA method. Two tests.

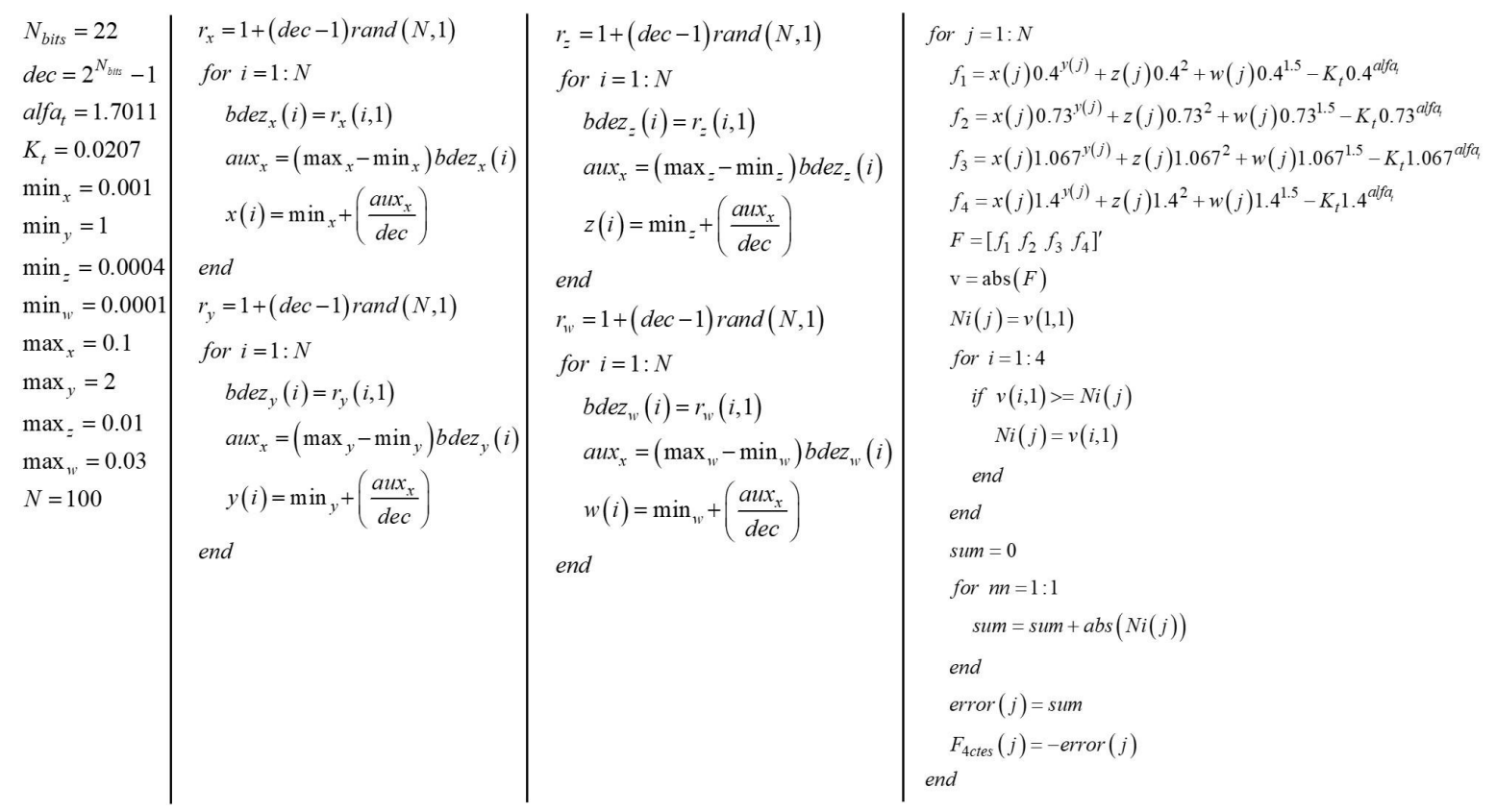

Fig. 17. Procedure of GA method. One test.

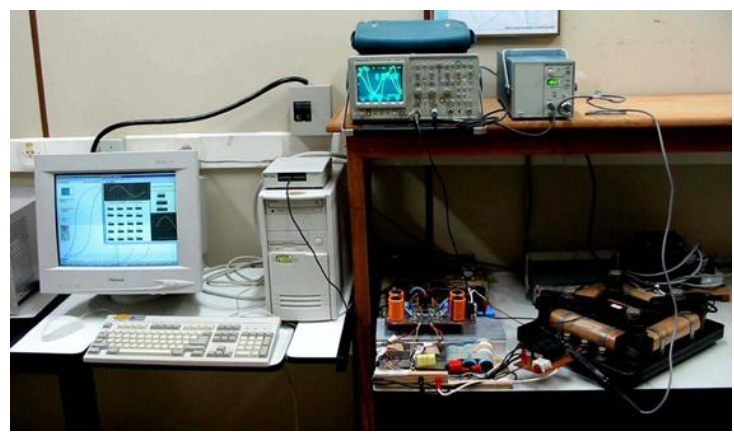

Fig. 18. Experimental workbench showing the Epstein frame, the drive and measurement system. 


\section{REFERENCES}

[1] D. Kowal, P. Sergeant, L. Dupré, and L. Vandenbossche, "Comparison of Iron Loss Models for Electrical Machines with Different Frequency Domain and Time Domain Methods for Excess Loss Prediction”, IEEE Transactions on Magnetics, vol. 51, Jan. 2015.

[2] S. Xue, J. Feng, S. Guo, J. Peng, W. Q. Chu, and Z. Q. Zhu, “A New Iron Loss Model for Temperature Dependencies of Hysteresis and Eddy Current Losses in Electrical Machines”, IEEE Transactions on Magnetics, vol. 54, Jan. 2018.

[3] S. Muller, M. Siegle, M. Keller, and N. Parspour, "Loss Calculation for Electrical Machines Based on Finite Element Analysis Considering 3D Magnetic Flux", in (XIII ICEM), 2018, pp. 1246-1252.

[4] D. Yarymbash, M. Kotsur, S. Yarymbash, and I. Kylymnyk, "An Accuracy Enhancement of Parameters Calculation of the Jiles-Atherton Model", IEEE Problems of Automated Electrodrive, pp. 1-6, 2020.

[5] E. Salloum, O. Maloberti, M. Nesser, S. Panier, and J. Dupuy, "Identification and Analysis of Static and Dynamic Magnetization Behavior Sensitive to Surface Laser Treatments Within the Electromagnetic Field Diffusion Inside GO SiFe Electrical Steels", Journal of Magnetism and Magnetic Materials, vol. 503, no. 7, pp. 166613, 2020.

[6] M. Zou, "Parameter Estimation of Extended Jiles-Atherton Hysteresis Model Based on ISFLA", IET Electric Power Applications, vol. 14, pp. 212-219, 2020.

[7] C. L. B. Silva, A. J. Batista, and B. P. Alvarenga, "Measurement and Prediction of Magnetic Losses in Silicon Steel Sheets", in Congresso Brasileiro de Automática, Campina Grande, 2012.

[8] M. Dadić, M. Jurčević, and R. Malarić, "Approximation of the Nonlinear B-H Curve by Complex Exponential Series", IEEE Access, vol. 8, pp. 49610-49616, 2020.

[9] E. J. Meurer, "Estudo das Perdas Magnéticas Interlaminares em Máquinas Elétricas", dissertação, Universidade Federal de Santa Catarina, Florianópolis, SC, 2005.

[10] G. M. R. Negri, "Estudo de Caso de Envelhecimento Magnético em Aços Elétricos de Grão Não Orientado de Baixa Eficiência”, dissertação, Universidade Federal de Santa Catarina, Florianópolis, SC, 2011.

[11] P. A. da Silva Júnior, "Bancada para Ensaios de Materiais Ferromagnéticos em Chapa Única sob Campos Rotacionais", Ph.D. dissertation, Universidade Federal de Santa Catarina, Florianópolis, SC, 2007.

[12] M. Schulter, "Aplicação de Algoritmos Genéticos na Modelagem de Transformadores a Partir de Ensaios”, dissertação, Universidade Federal de Santa Catarina, Florianópolis, SC, 2007.

[13] M. L. P. Pinheiro, "Caracterização e Modelagem da Histerese e das Perdas Magnéticas em Aços Elétricos através do ScaMMa”, dissertação, Universidade Federal de Goiás, Goiânia, 2016.

[14] J. F. R. Martelo, "Determinação das Propriedades Magnéticas de Aços Elétricos em Serviço e Utilizando o Método de Epstein”, dissertação, Faculdade de Ciências e Tecnologia, Universidade Nova de Lisboa, 2017.

[15] F. B. R. Mendes, J. V. Leite, N. J. Batistela, N. Sadowski, F. M. S. Suárez, and J. P. de Barros Neto, "Comparison and Combination of Techniques for Determining the Parameters of a Magnetic Hysteresis Model", Journal of Microwaves, Optoelectronics and Electromagnetic Applications, vol. 18, no. 3, pp. 408- 426, September 2019.

[16] N. J. Batistela, N. Sadowski, R. Carlson, and J. V. Leite, "Caracterização Magnética de Lâminas de Aço Silício e Evolução das Perdas no Ferro sob Vários Regimes de Indução", Sociedade Brasileira de Automática (SBA), São Paulo, Brasil, vol. 13, no. 1, pp. 156 - 164, 2002.

[17] J. P. A. Bastos, N. Sadowski, and N. J. Batistela, "Ferromagnetic Materials and Iron Losses", London/New York, 2013. 